\title{
The Economic Value of Local Social Networks
}

\author{
Tom Kemeny*, Maryann Feldman**, Frank Ethridge**, Ted Zoller** \\ * University of Southampton \\ ** University of North Carolina, Chapel Hill
}

This version represents the accepted, peer-reviewed manuscript, forthcoming at the Journal of Economic Geography. Please cite accordingly.

\begin{abstract}
The idea that local social capital yields economic benefits is fundamental to theories of agglomeration, and central to claims about the virtues of cities. However, this claim has not been evaluated using methods that permit confident statements about causality. This paper examines what happens to firms that become affiliated with one highly-connected local individual defined as a "dealmaker." We adopt a quasi-experimental approach, which examines firms which added exactly one new individual to their firm combining difference-in-differences and propensity score matching to address selection and identification challenges,. The results indicate that, when compared to a control group, firms who link to one highly-connected local dealmaker are rewarded with substantial gains in employment and sales.
\end{abstract}

JEL Codes: R11; O12; O18; L14

Keywords: social networks; economic development; social capital; firm performance

Acknowledgements: The authors would like to thank seminar participants at the Stanford Institute for Economic Policy Research, École Polytechnique Fédérale de Lausanne, CIRCLE (Lund University), LSE's Spatial Economics Research Centre, Dominik Hangartner, Max Nathan, Simona Iammarino, as well as two anonymous reviewers for insight, discussion, and advice that were helpful in revising this paper. Thanks also to the Ewing Marion Kauffman Foundation for providing financial support for this project.

Corresponding author: Tom Kemeny, University of Southampton, t.e.kemeny@soton.ac.uk 


\section{Introduction}

Since Alfred Marshall's (1890) observations about the circulation and propagation of ideas in English industrial districts, researchers have been motivated to understand if local social networks augment economic performance (Glaeser et al., 1992; Jaffe et al., 1993; Powell et al., 1996; Saxenian, 1994; Feldman and Audretsch 1996a; Casper, 2007; Breschi and Lissoni, 2009). This inquiry intersects with an interest in the idea of social capital throughout the social sciences, which suggests that a higher degree of network centrality increases pecuniary value (Coleman, 1988; Putnam, 1995). While social networks certainly reach beyond individual geographic agglomerations (Kenney and Patton, 2005), the myriad virtues of proximity suggest that cities are the relevant spatial unit for considering how interactions within social networks affect economic outcomes (Feldman and Audretsch, 1996ab; Storper and Venables, 2004; Duranton and Puga, 2004; Rosenthal and Strange, 2004; Whittington et al, 2009; Ellison et al, 2010). It is argued that, by lowering transaction costs, social capital can better foster trust and encourage information sharing. Hence, economic actors ought to earn higher returns in cities endowed with improved social networks.

Despite the pervasive folklore about place-based social networks, making confident statements about the existence of a causal relationship requires greater clarity on the mechanisms by which social networks improve economic performance (Jones 2006; Malecki, 2012). There is a limited evidence base to grapple with the profound endogeneity problems inherent in this relationship. Put simply, it is hard to tell whether 
denser networks are an independent cause of performance improvements, or whether the two are simply correlates.

This paper makes an original contribution to this debate in two ways. First, rather than defining local social capital in aggregate, it examines particular agents that prior research hypothesizes perform network-leveraging roles. Specifically, this paper examines unusually well-connected agents within regional networks, called 'dealmakers.' The term dealmaker is colloquial in entrepreneurship practice, and describes an accomplished actor who is deeply enmeshed in local social networks, and who uses their connections to 'make things happen' (Senor and Singer, 2009). These individuals are brokers of the kind described by Ronald Burt (1995), but with an observably local orientation, who live, participate, and invest in a place. Feldman and Zoller (2012) demonstrate that the presence of dealmakers in U.S. regions - not the aggregate size or density of local social networks - is strongly positively correlated with a region's rate of firm births in life sciences and information technology. This correlation could indicate either that dealmakers directly spur entrepreneurship or could reflect the reverse causal sequence: vibrant urban economies simply produce more dealmakers, without the latter having a strong independent effect. A third interpretation is that some as-yet unmeasured force determines both regional entrepreneurial dynamism and the existence of dealmakers.

This paper seeks to distinguish between these possibilities by observing what happens when individual firms add a dealmaker to their board or top management. In so doing, it seeks to test the hypothesis that, by lowering the costs of making connections and sharing ideas, locally well-connected individuals augment the economic performance 
of the firms to which they become connected. Specifically, the paper explores whether dealmakers leverage regional connections to influence firm performance, measured in terms of changes in its sales and employment. We also consider whether dealmakers' nodal positions in regional social networks could affect the trajectory of a firm by stimulating a liquidity event, thereby providing original entrepreneurs and investors with a means of converting their ownership equity into cash.

The second contribution of this paper is to embed this examination of microsocial dynamics in an empirical framework that can generate more confident statements about causality. The primary obstacle to identifying dealmakers' causal influence is that links between dealmakers and firms are endogenously related to performance. Simply, dealmakers are likely to be drawn to firms that promise success. To address this selection problem, this study adopts a quasi-experimental research design that combines propensity score matching with difference-in-differences estimation. Propensity score matching is used to model the selection process of dealmakers to firms, with propensity scores used to build a counterfactual group of firms that do not link to dealmakers (the control group), but who otherwise resemble those that do (the treatment group). To sharpen the comparison, control firms receive one new non-dealmaker, permitting clearer estimation of dealmakers' additionality relative to more typically-connected individuals. Propensity scores are then used in a difference-in-differences model that accounts for variation in the evolution of the two groups before and after the treated group receives the treatment.

Combining these approaches confers benefits. Above all, it allows us to control for observed as well as stationary unobserved properties of individual firms that ought to 
influence the likelihood of a dealmaker's involvement. Researchers studying politics and economic policy have used such approaches to answer a wide variety of questions (see for instance, Ashenfelter, 1978; Card, 1994; Heckman et al, 1997; Grogger and Willis, 2000; Groen and Povlika; 2008; Hausman, 2012), sometimes using them in combination (Arnold and Javorcik, 2009; Görg, and Strobl, 2007). Quasi-experimental approaches are underexplored in economic geography and offer one means of accounting for endogeneity problems that pervade a good deal of research in this field. In terms of the specific context of the present study, they have not yet been used - whether together or separately - to estimate the relationship between interpersonal networks and firm performance.

To carry out this research design, a set of 325 firms in life sciences and information technology sectors, located in 12 U.S. high- technology regions, are observed in two time periods: December 2009 and December 2012. Between these two waves, each of the 325 firms add exactly one new individual to their board or management team: 15 firms add an individual who was a regional dealmaker, while 310 firms add an individual with a more typical number of connections to the network of firms. The former collection of firms are those that receive the 'treatment,' the latter constitute the control group. Capital IQ, one of the more comprehensive data sources on entrepreneurial firms available in the United States, provides the sampling frame of firms and dealmakers. We link these data to information obtained from Dun \& Bradstreet (D\&B), which provides a wealth of establishment-specific characteristics, such as international trade activities; creditworthiness; ownership structure; as well as employment and sales. 
We find that, compared with similar firms that do not get dealmakers, firms that become affiliated with dealmakers have considerably higher growth in sales and employment. However, becoming affiliated with a dealmaker does not influence the likelihood of acquisitions. In light of the motivating theory, our results suggest that dealmakers' attempts to leverage local social networks actually enhance the performances of firms to which they are connected.

The remainder of the paper is organized as follows. Section II reviews the literature on networks and economic performance. Section III lays out our conceptual framework. Section IV describes the empirical approach taken, and Section V describes our data. Section VI presents diagnostics of the analytical procedure. Section VII presents results. Section VIII concludes.

\section{Linking Social Networks and Economic Performance}

Our research is situated at the intersection of two conversations in the social sciences. The first conversation emerges from economy geography, and asserts that, despite strong secular declines in spatial transaction costs, many forms of productionand especially those intensively involving knowledge - remain decidedly, and perhaps even increasingly place-bound (Glaeser et al., 1992; Saxenian, 1996; Storper, 1997; Storper and Venables, 2004). Interest in this topic is acute because these knowledgeintensive activities come with large pecuniary rewards, both because they involve unusually productive workers, and because various factors, including technological 
change and a certain form of deep global integration, appear to have together diminished the viability of many other pathways to place-based economic development, especially in high-wage locations.

External economies of scale underlie these benefits: as larger numbers of firms and workers cluster together, firms are said to benefit from larger labor pools, from minimization of coordination costs among buyers and suppliers, and perhaps most importantly, from spillovers of tacit knowledge (Marshall, 1890; Duranton and Puga, 2004; Combes and Gobillon, 2014). In these channels, linkages among individuals in space - local social networks - act as a central motor force. And yet, in much of the empirics supporting these propositions, these interpersonal and interfirm interactions have been captured in a highly abstract way, with many influential studies operationalizing linkages using simple co-presence in the same location, typically measured at a highly aggregated scale (for instance, see Henderson, 2003; Moretti, 2004).

Some strands of this research program are explicit about modeling these latent but constitutive networks, especially among researchers focused on capturing the spatial aspects of the dissemination of novel ideas, whether capturing the localness of the flow of knowledge through citations between patents, or by examining networks formed among partner inventors (Jaffe et al, 1993; Thompson, 2006; Lobo and Strumsky, 2008, Breschi and Lissoni, 2009). Networks also are implicit in examining spinoffs as a driver of agglomeration (Casper, 2007; Casper and Murray, 2005). With a few exceptions however, network structure is ignored, or considered only in an aggregate sense (Carlino and Kerr, 2014). Meanwhile, case studies, like AnnaLee Saxenian's (1994) influential study of 
Route 128 and Silicon Valley, highlight the importance of micro-interactions within a broader social milieu - think of computer hardware and software engineers sharing ideas over beers in Mountainview's Walker's Wagon Wheel. While such work is crucial, it operates in a research framework that privileges depth and texture over the ability to maximize internal validity by accounting for myriad confounding issues.

The second overlapping conversation draws on the work of sociologists and organization-focused researchers. This work strikes against an atomized individual- and firm-centric view of the economy, and instead considers that social interactions among these elements importantly enable and constrain economic behavior (for reviews, see Podolny and Page, 1998; Borgatti and Foster, 2003). In this context, networks are the infrastructure through which relationship-specific advantages - social capital - are created, sustained and distributed. Networks confer legitimacy, spread ideas, improve governance, and augment the matching abilities to tasks (Dyer and Singh, 1997). The broadest prediction arising from this work is that, all else equal, more highly connected economic agents will reap higher rewards than more isolated agents. Theorists also argue for a distinction between being better and more connected, with Burt $(1995,2004)$ for instance, arguing that brokers -individuals that are able to span disparate network nodes have access to a wider variety of information, heuristics and talent, and as such are uniquely important generators of social capital. The implication is that it is not merely a larger number of overall connections that ought to matter for economic performance; rather, qualities of those connections matter as well.

Empirical studies motivated by this general framework have considered the links 
between properties of networks and a wide variety of economic outcomes, from job search efficiency (Granovetter, 1973), to reputation (Shane and Cable, 2002), to innovation (Ahuja, 2000). A considerably smaller subset of research examines the topic of direct measures of firm performance. Among these, the most directly relevant is the work of Walter Powell and co-authors. For instance, examining the evolving U.S. biotechnology industry, Powell et al (1996) find that the number of collaborations a firm undertakes, as well as its centrality in interfirm networks are significant predictors of employment growth and the likelihood of having an initial public offering. Powell et al (1999) confirms the importance of network centrality to biotech firms, finding positive links to nonoperating income and sales. With mixed results, subsequent research has examined the relationship between interfirm alliances and various measures of knowledge creation, and to a lesser extent, wider indicators of firm performance (see for instance, Sampson, 2007; Lavie, 2007, Ozcan and Eisenhardt, 2009).

A related literature considers a different channel through which performanceinfluencing networks are formed: corporate board interlocks. Having well-connected board members is theorized to have potential positive and negative impacts. Central boards could improve firm performance by helping to spread ideas (Mizruchi, 1990); leveraging contacts (Mol, 2001); reducing information gaps in contracting (Schoorman et al, 1981); and spurring interfirm competition (Pennings, 1980). Central boards could inhibit performance to the extent that channels of knowledge convey ideas that reduce firm value (for instance, see Bizjak, 2009), or because highly-connected directors have little time to focus on any single organization in their network (Fich and Shivdasani, 
2006). The empirical literature bears out this ambiguity (Dalton et al, 1999; Carpenter and Westphal, 2001), through recent research on a very large sample of firms finds that, all else equal, firms whose directors have high levels of network centrality earn higher profits and outperform stock market expectations (Larcker et al, 2013).

Each of these conversations has strengths and weaknesses. While economic geographers and other city-focused researchers generally either abstract away from direct network interactions, or privilege close analysis over generalizability, the discussion in sociology and management mostly ignores the role of geographical space in which such interactions may take place. Only two known studies straddle this divide. Whittington et al (2009) consider how metropolitan-specific and global partnerships among U.S. life sciences firms are related to their patenting activity, and find evidence that both kinds of networks are independently and positively linked to patenting. Whittington et al (2009) do not distinguish particular kinds of agents, instead contending that firms that enjoy more connections, and greater diversity among those connections ought to outperform their peers. Feldman and Zoller (2012) have a distinctive approach. Rather than measuring firms' connectedness in networks, they start from the local embeddedness of unusually connected individual agents, and consider how the presence of such agents may be related to measures of local entrepreneurial vibrancy. This work explores simple correlations, with no causal claims made, but suggests that there is a potentially important distinction to be made between people with average levels of network connections and super-connected dealmakers, who bring greater novelty and exposure to different ideas. The goal of the present paper is to deepen our understanding of this latter hypothesis. 


\section{Conceptual Framework}

Consider a universe of firms in a location, where each firm's performance is a function of the quality of its workers, firm-specific attributes such as capital, as well as some industry- and region-specific factors. Among the salient drivers of worker quality is the ability to leverage interpersonal connections, or social capital, for the potential gain of the organization (Giuri and Mariani, 2013). Through connections to the regional social network, workers can gain new ideas and human capital that might raise productivity, open new markets, help develop new products, or stimulate mergers, acquisitions or other types of liquidity events. Through these channels, the social network can affect firm performance. By extension, regional economic outcomes will be a function of the performance of individual firms (Saxenian, 1993; Uzzi, 1995).

Workers vary in terms of their position in local social networks. For simplicity, we assume there are two kinds of workers: those that have standard access to the network, and those with a greater quality of social capital, occupying privileged network positions. For simplicity, we call the more highly connected workers dealmakers, while we call workers with average social capital non-dealmakers. There is a need to consider effects arising not just from dealmakers but also from association with non-dealmakers. Concretely, the combined network connections of non-dealmakers could equal or exceed the reach of a typical dealmaker. Given this potential confounding issue, we must account for the social capital of both kinds of network actors.

Given this framework, we describe firm performance as follows: 


$$
f\left(Y_{p}\right)=\left\{l_{\text {iin }}, i_{\pi i n_{2}}, K_{p 1}, R\right\}
$$

where $y$ measures firm performance of firm $p$ in region $r ; l_{d m}$ measures the number of dealmakers affiliated with the firm, while $l_{n d m}$ captures the presence of non-dealmakers; $K$ captures firm-specific characteristics; and $I$ and $R$ describe industry- and region-specific factors. Our aim in this paper is estimate the independent causal effects of $l_{d m}$ on $y$, holding constant other drivers of performance. A description of our empirical approach follows.

\section{Empirical Approach}

We expect that dealmakers will elicit positive changes in the performance of firms with which they become affiliated. There are at least three empirical approaches to assess the potential effect of associating a dealmaker to a firm. First, the performance of firms after they get a dealmaker could be compared to their pre-dealmaker performance. But, irrespective of any causal dealmaker effects, with this approach any results could reflect unobserved time trends in the performance outcome or some economy-wide shock.

Second, the performance of firms that receive the treatment of working with a dealmaker may be compared to a control group of similar firms that lack an affiliated dealmaker. This method, however, risks assigning explanatory value to dealmakers that reflects preexisting inter-group differences. This poses a particular problem for the proposed research, because there is good reason to believe that: (a) firms that become linked to 
dealmakers differ from those that do not, and (b) these differences bear upon their performance. Put simply, there could be a selection effect as dealmakers ought to be drawn to firms that have demonstrated success, or show great promise to succeed (Jaffe 2002). This selection process between dealmakers and firms would bias conventional regression approaches and overestimate the impact of adding a dealmaker.

To address these issues, this study adopts a third approach that combines beneficial aspects of the previous two. Specifically, this study considers firm performance before and after adding an executive or board member, while also comparing firms that become affiliated with a dealmaker (the treatment group) to others that receive a non-dealmaker (the control group). For precision, the sample of firms is initially limited to those that have zero dealmakers in the pre-treatment period. The treatment group is treated by the addition of exactly one dealmaker, with zero nondealmakers added. The control group does not add a dealmaker, but adds one nondealmaker. The analysis combines the difference-in-differences (DD) estimator with propensity score matching (PSM) techniques. As a first step, the Epanechnikov kernelbased PSM procedure estimates the likelihood of each firm linking to a dealmaker, conditional upon a vector of observed firm characteristics. The resulting probabilities are then used to match treatment and control firms such that, for a limited subset of cases, systematic differences across the groups can be eliminated (Dehejia and Wahba, 2002). From these probabilities, weights are generated that indicate the relevance of each control firm to each treatment firm. These weights are then applied to a regression-based difference-in-differences model. Though it does so in a regression context, in essence this 
estimator compares changes in firm performance between pre-and post-treatment periods across the treatment and control groups, as follows:

$$
a^{i}=\left(\bar{Y}_{i 1}^{r}-\bar{Y}_{i 1}^{c}\right)-\left(\bar{Y}_{t 0}^{Y}-\bar{Y}_{i 0}^{C}\right)
$$

where $t$ measures the average effect of the treatment on the treated, $T ; Y$ represents the outcome of interest; $\mathrm{C}$ indicates the control group; and $\mathrm{t}_{0}$ and $\mathrm{t}_{1}$ represents the pre- and post-treatment periods, respectively.

Both PSM and DD come with identifying assumptions. For propensity score matching to be effective, the treatment and control group must be balanced, postmatching (Rosenbaum and Rubin, 1983). Balance, or conditional independence, is achieved when there are no significant differences in pre-treatment covariates across the matched treatment and control group, except for the treatment itself. In this manner, propensity score matching mimics random assignment (Pearl, 2000).

The primary limiting assumption of the DD approach is that the performance trajectory of the control group ought to reflect what would happen to the treatment group in the absence of the treatment. This 'parallel trend assumption' cannot be directly tested, since one cannot observe the evolution of the treatment group absent the treatment; firms are either treated, or they are not. Nonetheless, some confidence regarding parallel trends can be generated by estimating a placebo test, in which, for the same treatment and control groups, PSM and DD results are generated across an earlier time period during which the 'treated' group does not actually receive the treatment. In other words, this 
approach tests whether there are significant differences in the evolution of a given performance criterion over a period in which, in actuality, no treatments are assigned. While this does not eliminate the possibility that firms' trajectories shift after this earlier wave, parallel paths in the past provide the best available gauge of the similarity of subsequent pathways across the group of firms that receive dealmakers and its counterfactual.

These represent strong assumptions, but, if satisfied, PSM and DD are strongly complementary. Specifically, with PSM alone, one must assume that observable firm features sufficiently capture the important differences driving selection. And yet, although we know they matter, entrepreneurial characteristics like brand, talent, and hustle are nearly impossible to systematically observe. Fortunately, as in a standard fixed effects model of which it is a particular variant, DD eliminates bias from time-invariant unobserved firm heterogeneity, as well as from broad economic shocks (Blundell and Costa Dias, 2000). This means that, even if we cannot capture the full range of hard-tomeasure differences that distinguish more- and less- promising entrepreneurial firms, as long as they are rooted in enduring firm characteristics, we can account for them econometrically. Arguably, many, though not all, important firm characteristics will be relatively stationary. This still leaves potential for confounding on the basis of dynamic unobservable variables. For instance, two firms that have followed parallel trajectories, and that are endowed with identical human, physical and financial assets might still diverge as one makes a sudden and major breakthrough that both shifts their performance path and also draws the attention of a dealmaker. This caveat noted, as compared with 
prior work, the econometrics used here represent a considerably stronger basis upon which to consider causal effects of social networks.

For each outcome of interest, the basic sequence to be followed is: (1) estimate propensity scores; (2) evaluate matching quality with respect to balance on observables and the degree to which parallel trend assumption is likely to be upheld; (3) to produce difference-in-differences estimates on firms that fall within the common support area. If the assumptions described above can be satisfied, the results ought to efficiently estimate the average treatment effects of those firms that become linked to dealmakers.

\section{Data}

Capital IQ, a private database maintained by Standard \& Poor's, provides the sampling frame of firms and individual actors. Capital IQ is one of the more comprehensive data sources on private firms available in the United States, capturing those that have received bank, private-equity or venture capital financing. Crucially, these data provide extensive biographical information about firms' management and board members. For simplicity, we will refer to these individuals collectively as 'top teams.' On the basis of the links between these individuals, we are able to construct regional social networks and, most crucially, to distinguish dealmakers from non-dealmakers.

Networks are constructed from links among top team members that are associated with firms in two broad industry categories: life sciences and information technology. ${ }^{l}$ These are sectors in which local inter-firm interactions, spinoffs and networks are legendarily important (Saxenian, 1994; Audretsch and Feldman, 1996a; Feldman, 2000; 
Owen-Smith and Powell, 2004, Casper, 2007), making them apt sites at which to look for the economic effects of place-based social networks. We build such networks for 12 U.S. regional economies: Austin, Boston, Denver, Minneapolis, Orange County, Phoenix, Portland, Raleigh-Durham, San Diego, San Francisco, Salt Lake City, and Seattle. ${ }^{2}$ These regional economies represent the largest spatial concentrations of employment in these activities in the U.S. With these constraints, Capital IQ permits consideration of networks among approximately 85,000 individuals and 22,000 firms. Some degree of completeness is important to the examination at hand; our snapshot should correspond reasonably closely to actual regional networks. One potential problem arising from incompleteness is that certain individuals who we define as being only moderately connected to the network might actually emerge as dealmakers if we captured more of the underlying network. This might blur the lines between our treatment group and our control group, resulting in greater odds of a false negative. To more confidently describe our networks as complete, the firm list generated by Capital IQ was compared against data from Thomson Financials Venture Xpert, a series that captures firms with similar success at securing financing. This comparison supported the use of Capital IQ as a sound basis for the exercise at hand.

\section{[TABLE 1 HERE]}

Interlocks among top team members and their firms in the Capital IQ data are used to evaluate the degree to which agents are connected to multiple local firms and 
therefore involved in the social milieu of a local economy. Our primary definition of a dealmaker follows that of Feldman and Zoller (2012), in which dealmakers have at four or more concurrent ties as executives or board members in other firms in the region. As Table 1 makes clear, these multiple roles and interconnections indicate an unusual degree of imbrication in regional networks; using data for 2009, while 90 percent of identified actors are connected to one firm in their location, just over one percent would be classified as a dealmaker. ${ }^{3}$ There is some variation from city to city; notably, the San Francisco Bay Area and Boston host a proportionately larger numbers of dealmakers within their absolutely larger regional networks. However, the table shows that broad patterns in the distribution of dealmakers are consistent across cities.

Substantively, top team members are expected to play particularly important roles in determining firm performance, and especially in terms of harnessing local social capital. Top management is tasked with the development of the organization, while boards of directors are intended to act independently to advise the executive on strategic direction (Larcker and Tayan, 2011). In the United States, public companies are legally obligated to have a board of directors. Service as a director in a public companies is highly regulated; and as a consequence of the Sarbanes-Oxley Act of 2002, members of the board and officers are legally liable for the direction of the firm, as a result of their substantial fiduciary obligation and connection to it. A privately-held organization may choose to have a board, and these are especially common in biotechnology and other high technology sectors (Lerner, 1995). Board members on private firms have the opportunity to play a larger role in the direction and development of the organization. They are 
typically paid a salary, though commonly one that is intended to complement rather than replace other paid work. Our focus on top team members means that we ignore possible benefits that could arise from changes in firms' workforces outside these upper echelons. We adopt this restriction for practical as well as substantive reasons. Practically, while interlocks across executives and board members represent well-mined and effective input into network-building, there exists no comparable data source available to capture interfirm interactions among non-elites. We also only consider executives' and directors' formal links among each other, ignoring informal connections that might matter. On this latter point, prior research suggests that formal and informal connection ought to be strongly correlated: individuals through who are unusually well-connected in terms of formal linkages are also likely to be very well connected through informal channels (Westphal et al, 2006).

To evaluate outcomes, two waves of Capital IQ data are examined: a pretreatment wave, collected in December 2009, and a post-treatment wave from December 2012. The criteria for inclusion in the primary analytical sample are that (1) firms have zero attached dealmakers in 2009; (2) that they continue to exist in 2012; (3) that treated firms add exactly one dealmaker and zero non-dealmakers between December 2009 and December 2012; and (4) that control firms add exactly zero dealmakers and one nondealmaker between 2009 and 2012. These are narrow criteria, which, along with moderate attrition arising from the matching process across different datasets, produce an analytical sample of 325 firms that spans the full range of regional economies in the larger data. 


\section{Outcomes and Matching Parameters}

Outcomes are drawn from Dun \& Bradstreet (D\&B)'s DUNS Marketing Information database. The 2012 D\&B snapshot is drawn directly from D\&B. The 2009 snapshot is part of a longitudinal series from 1990 to 2011, sourced from the National Establishment Time Series (NETS), which compiles repeated cross-sections of the underlying D\&B data on employment, sales and other variables into a longitudinal series. D\&B tracks establishments, not firms, hence identified non-headquarters establishments are dropped from the sample. D\&B establishment records are linked to Capital IQ firms through DUNS identification numbers assigned using a proprietary matching and disambiguation algorithm by $\mathrm{D} \& \mathrm{~B}$.

In the analysis below, we consider that dealmakers might influence various performance outcomes. Of particular interest are sales and employment. Growth in sales and employment could reflect the influence of dealmakers on the incorporation of new ideas in product or marketing; they could also indicate actual deals made with other firms. Especially in information technology, profit measures are a more imperfect performance indicator, since many 'successful' firms do not make a profit for a lengthy time periods. Dealmaker affiliations could also stimulate liquidity events. These come in three main forms. A firm's immediate corporate parent can change, reflecting an acquisition. It can also merge with another pre-existing firm, or it may shift from privately-held to publiclylisted, with an initial public offering (IPO) of stock. Each of these represent an exit strategy for the entrepreneurial firm, enabling owners and initial investors to yield a 
financial return in exchange for surrendering or diluting their ownership stake in the company. Finally, we are interested in observing whether there is a relationship between dealmakers and new (and pending) rounds of investment. Unfortunately, we found that only a small number of firms experienced IPOs, mergers, or new investments over the study period, and after matching, none of these firms was deemed sufficiently comparable across the treatment and control groups. Hence, in the results below we focus on the association between dealmakers and sales, employment, and acquisitions.

Parameters used to match treatment and control firms should have some predictive power for both selection into the treatment and the outcome of interest. Moreover, they ought to be unaffected by the treatment. To address the former concern, a wide variety of firm characteristics ought to factor into dealmaker affiliation decisions, and these are similarly likely to be related to sales, employment and the other outcomes of interest. On the latter point, the data for matching comes from 2009 and earlier before the treatment occurs. These data come mostly from $\mathrm{D} \& \mathrm{~B}$, and capture a wide variety of establishment characteristics. ${ }^{4}$ Across various outcomes we select a consistent group of covariates, including: lagged levels of sales and employment; the quartile of the firm's last three years of sales growth relative to 3-digit SIC peers; the number of affiliated non-dealmaker executives and board members; the total number of network connections held by affiliated non-dealmakers; detailed industry; metropolitan region; founding year; Paydex and D\&B credit scores; legal status; gender of the Chief Executive Officer; ethnic minority ownership; ownership by women; whether the firm has moved more than once between 1990 and 2009; whether the organization engages in government 
contracting; and the firm's involvement in importing and exporting activity.

\section{[TABLE 2 HERE]}

Table 2 presents descriptive statistics for the treatment, as well as for primary outcomes and key matching parameters. Of the analytical sample of 325 firms, just under five percent of firms add one dealmaker over the three-year study period. The average firm in the sample has 72 workers, and has sales of $\$ 13$ million. The average firm in the sample was started in 1993, thus reflecting not early stage startups but more established going concerns. Most of the firms are incorporated, and just over half engage in some form of international trade. A typical firm in the sample has almost 9 non-dealmaker top team members, including board of directors, and collectively these individuals have an average of 9 local affiliations. ${ }^{5}$

\section{Results}

Table 3 presents difference-in-difference estimates comparing propensity-scoreweighted treatment and control groups (results of the propensity score probit estimation shown in Appendix A). Given satisfaction of the identifying assumptions, which we explore in depth below, the result is the average treatment effect on the treated (ATT). In this inquiry this represents estimates of the causal effects of dealmakers on firm sales, employment, and the likelihood of acquisition. Results are estimated only on the common 
support region, that is, firms in both groups that are deemed sufficiently comparable in terms of pre-treatment covariates (Heckman et al, 1998). Following the 'maxima and minima' approach (Caliendo and Kopeinig, 2008), a treatment firm is dropped from the common support region and the regression when its estimated propensity score is higher than the maximum or less than the minimum propensity score of the controls. Though, in the current context, this represents a considerable trimming of the analytical sample, there can be no effective estimation of the treatment effect without it, especially when matching is performed via kernel, as against nearest-neighbor or other methods (ibid).

\section{[TABLE 3 HERE]}

The leftmost panel of Table 3 presents estimates for dealmaker effects on firm sales. In 2009, both treatment and control groups have very similar levels of sales; yet post-treatment, they have evolved quite differently. While sales levels grow for both groups, firms that become affiliated with a dealmaker experience considerably more sales growth as compared to those firms that add one non-dealmaker. The effect, as measured by the ATT, is statistically significant at a 5\% level and strikingly large: an increment of just over $\$ 13$ million in sales. The common support region is relatively narrow, as 9 treatment firms are compared to 22 firms in the control group, signifying that a good number of the overall sample of 80 treatment firms have no appropriate analogue in the control group. 
The middle panel of Table 3 reports results for the employment outcome. Here, treatment and control groups in the common support region are fairly different in size at the outset, with firms who later become affiliated with a dealmaker being somewhat larger in the pre-treatment period than those that do not. Again, the ATT reveals large, positive and statistically significant dealmaker effects. Employment in firms that receive a dealmaker over the study period grows relatively more. In fact, while control firms add just a handful of workers over the three-year period, the dealmakers stimulate roughly a doubling of the workforces of treated firms.

The rightmost panel of Table 3 presents estimates of the causal influence of dealmakers on the likelihood of acquisition. No firms in the sample experience an acquisition in 2009, hence values during the pre-treatment period are uniformly zero. By December 2012, 20 percent of treatment firms change their immediate corporate parent, as against only 4 percent of control firms. And although the coefficient on the ATT is large and positive, it has a standard error that is nearly as large, indicating that dealmakers exert no significant influence on the likelihood of a firm experiencing this kind of liquidity event.

Overall, these results suggest that dealmakers exert an independent causal effect on the sales and employment of firms with which they become affiliated. Firms that add one dealmaker and zero non-dealmakers outperform closely comparable firms that add one non-dealmaker and zero dealmakers. To the extent that these dealmakers generate such effects through their marshaling of local social networks and social capital, this signals that such local networks do indeed have economic value. The fact that we find no 
significant results for acquisitions suggest that dealmakers do not chiefly catalyzing formal deals in which entrepreneurial firms are acquired.

\section{Robustness \& Sensitivity}

To have some confidence in interpreting these results as indicating that dealmakers cause beneficial changes in firm performance, we need to demonstrate the satisfaction of the conditional independence and parallel trend assumptions. Conditional independence is satisfied if, for observed pre-treatment covariates $x$, the conditional distribution of $x$ is the same for both the treatment group and the control group (Rosenbaum and Rubin, 1983). Table 4 reports $t$-test comparisons on the raw (unmatched) and post-propensity-scorematched samples, for each of the three outcomes of interest. To the extent that we observe insignificant $p$-values on this test for the matched sample, we can conclude that balance has been achieved, affirming the validity of the use of the control group as a counterfactual for the treated.

\section{[TABLE 4 HERE]}

The evidence presented in Table 4 suggests that the matching procedure achieves balance for each of the outcomes of interest. Mean values of these variables do not vary across the matched sample in a statistically significant manner, despite, at times, highly significant differences observed in the unmatched sample. This means that there are important, pre-existing differences between those firms that become affiliated to 
dealmakers and those that do not, but, using the covariates listed in Table 4 and their related propensity scores, it is possible to construct a counterfactual in which these differences are no longer significant. The balance reported in Table 4 should raise confidence that the main effects reported in Table 3 are derived from an appropriate comparison between firms whose primary difference is their 'assignment' to treatment.

The second major assumption to be satisfied is the parallel trend condition, requiring that treatment firms would be progressing along a comparable trajectory to control firms in the absence of treatment. This is a strong assumption, and it is never possible to be entirely certain of its satisfaction. However, data from the past can help detect, if not definitively test for a parallel trend.

\section{[TABLE 5 HERE]}

In Table 5, we report the results of a placebo test, in which, for sales and employment outcomes, the entire sequence of analysis is reproduced for the period 2006 to 2009. Over this period, in actuality, no firms in either the treatment group or the control group receive the treatment. ${ }^{6}$ Put another way, we compare whether firms that receive the treatment between 2009 and 2012 have evolved differently from the control group over the previous three years. If treatment and control firms are following a parallel path, we should expect no significant effects of placebo dealmakers on firm performance. If treatment firms are already on their own distinct trajectory, the placebo 
association with a dealmaker will appear to significantly influence the outcome of interest. Table 5 shows that average placebo treatment effects are statistically insignificant, suggesting that, in this earlier period, the sales and employment pathways of the placebotreatment group and the control group run in parallel.

Given the narrow common support region, we consider some additional ways to explore the sensitivity of the main results to changes in the treatment and sample. Specifically, we first relax the strictness of the treatment, dropping consideration of changes in non-dealmakers, as well as the number of dealmakers added, such that the treatment becomes going from zero to at least one dealmaker, while control firms simply have zero dealmakers throughout the study period. This results in a sample of 394 treatment firms and 4,082 control firms. Despite the virtues of this larger size, however, the loss in the precision of the comparison results in insignificant findings for all four outcomes of interest. The same holds true when the treatment is further relaxed to include firms that receive at least one dealmaker, regardless of how many dealmakers affiliations are held in 2009.

One possible qualification of the main results is the possibility that dealmakers perform systematically different functions in firms of different ages. Firms in the startup phase might require dealmakers to plug them into the network of talent and ideas, whereas, for more experienced firms, dealmakers may make other resources available. Much of the literature emphasizes entrepreneurial firms, which can be interpreted as including only those that are in earlier phases of their development. And yet, as the mean values for 'First year of operation' presented in Table 2 indicate, the average treatment 
and control firm included in the primary analytical sample are more than 15 years old at the start of the study period.

Acknowledging the already small common support region, an additional challenge in exploring this idea is the availability of data about younger firms. Data sources like D\&B and Capital IQ tend to privilege older firms, simply because younger firms typically leave much less of a paper trail. Hence while we would like to produce estimates like those in Table 4 for only young firms, we cannot do so. The closest we can come is to use the 'relaxed' treatment described in the previous paragraph, and limit analysis to firms born after a particular cutoff. Even so, the number of relevant observations is small. Two thresholds are explored: a start year of 2005 and later; and more generously, 2002 or later. In the former case, firms are a maximum of 4 years old when the study period begins, in the latter case, seven years. With the 2005 threshold, the result is an analytical sample of 1,596 firms, out of which 476 become affiliated with a dealmaker. Again however, it appears that the imprecision of the comparison yields insignificant results: getting at least one dealmaker over the study period is not significantly associated with changes in sales, employment, or acquisition in these younger samples.

\section{Conclusion}

Accounts of thriving urban economies, both popular and scholarly, assert the importance of social capital and social networks. Theory in economy geography supports this idea, postulating that, by generating agglomeration economies, intra-locational 
interactions among firms and workers are the fundamental reason why cities exist. At the same time, much of the supporting empirics abstracts these interactions away. Meanwhile, sociologists have more explicitly explored the links between social networks and economic performance, though, in doing so they have mostly ignored the conditioning role of geographical space. Nonetheless, research suggests that firms that are better connected in social networks perform better across a range of performance measures.

This paper makes a unique contribution to these two literatures. We provide a measure of local social capital that links social networks to the top management of firms. Specifically, the analysis identifies highly connected individuals who bridge disparate parts of local social networks through their multiple locally-oriented roles. This paper has then applies a quasi-experimental approach in order to examine what, if anything, happens to firms when dealmakers join the firm as executives and directors, as compared to firms that receive only a typically-connected board member or executive. The strength of the empirical test rests on the combination of propensity score matching and difference-in-differences, together yielding an improved counterfactual to account for selection on dynamic observables as well as stationary unobservables.

We find that dealmakers in the 12 U.S. study regions exert an independent and large influence on firm employment and sales, but have no effect on the likelihood of getting acquired. We interpret this result to mean that dealmakers have an organizing effect on local social capital, yielding specific kinds of benefits for the firms to which they become affiliated. Dealmakers are one way that firms can become better connected in a regional economy, permitting better leverage of regional social capital that promotes 
firm growth.

Further research should address limitations and several unanswered questions. One important limitation of this paper is that we are unable to distinguish between effects derived from dealmakers' social and human capital. Indeed, quite plausibly the two are deeply interconnected, since unusually well-connected local players may well be endowed with human capital attributes, like talent, hustle, vision, and charisma. These characteristics ought to draw others to them, but they are also likely to contribute directly and independently to firm performance. The endogenous nature of this relationship, as well as the likelihood of a very strong correlation between human and social capital means that researchers are unlikely to resolve this issue econometrically. Well-designed mixed methods research represents a promising avenue to address such issues in future work, and more generally as a means of exploring precisely how dealmakers differentially affect the firms to which they are linked.

A second important limitation has to do with the achievement of balance between internal and external validity. As befits a first empirical test of the dealmaker hypothesis, this paper seeks to maximize confidence that the measured relationship indicates a causal link running from dealmakers to firm performance. To do so, it applies very strict criteria for inclusion in both the treatment and control groups, with the result being considerable attrition in the overall sample. As a result, while the results above give us some confidence that the treated firms actually benefit from the treatment, questions remain about how such a treatment might influence a different collection of firms. Facing this tradeoff, we have explicitly privileged internal validity, and the nature of our data makes 
this tradeoff potentially important. Future work should make addressing this point a high priority. Future work ought to explore the general importance of the finding made by the present study.

A third limitation is the possibility that bias is introduced through a firm-specific shock between our two waves of data. Though the two sets of firms are moving in parallel in a prior period, a key but unobserved breakthrough or advance during the actual study period could be both drawing dealmakers and spurring performance improvements. More fine-grained information about the timing of dealmaker links and firm status could help limit bias from this source - though it is unlikely that the potential for bias of this kind can be eliminated completely.

We hope that subsequent research will extend our approach and also explore a considerable number of unanswered questions. These include deeper exploration of the relationships between dealmakers and firm age; the potential importance of not just local but also nonlocal links; potential dealmaker effects on additional outcomes such as liquidity events and firm survival; greater sensitivity tests on the thresholds at which dealmakers may exert influence; exploration of potential long-run impacts; as well as how different means of increasing a firm's network centrality through individual connections may differently condition outcomes. Given the longstanding interest in the economic value of local social networks, and theoretical and anecdotal focus on highly connected individuals performing brokerage functions, these issues merit further exploration. 


\section{References}

Matthias Arnold, J., \& Javorcik, B. S. (2009). Gifted kids or pushy parents? Foreign direct investment and plant productivity in Indonesia. Journal of International Economics, 79(1), 42-53.

Ahuja, G. (2000). Collaboration networks, structural holes, and innovation: A longitudinal study. Administrative science quarterly, 45(3), 425-455.

Ashenfelter, O. (1978). Estimating the effect of training programs on earnings. The Review of Economics and Statistics, 47-57.

Audretsch, D. B., \& Feldman, M. P. (1996a). R\&D spillovers and the geography of innovation and production. The American economic review, 630-640.

Audretsch, D. B., \& Feldman, M. P. (1996b). Innovation in Cities: Science-based Diversity, Specialisation and Local Competition R\&D Spillovers', European Economic Review, 43, 409-29.

Bertrand, M., Duflo, E., and Mullainathan, S. (2004). How much should we trust differences-in-differences estimates? The Quarterly Journal of Economics, 119(1):249-275.

Bizjak, J., Lemmon, M., \& Whitby, R. (2009). Option backdating and board interlocks. Review of Financial Studies, 22(11), 4821-4847.

Blundell, R. and Costa Dias, M. (2000). Evaluation methods for non-experimental data. Fiscal studies, 21(4):427-468.

Bourdieu, P. (1986). The forms of capital. Handbook of Theory and Research of for the Sociology of Education.

Breschi, S. and Lissoni, F. (2009). Mobility of skilled workers and co-invention networks: an anatomy of localized knowledge flows. Journal of Economic Geography, 9(4):439-468.

Burt, R. S. (1995). Structural Holes: The Social Structure of Competition. Harvard University Press.

Burt, R. S. (2004). Structural holes and good ideas. American Journal of Sociology, 110(2):349-399.

Caliendo, M., \& Kopeinig, S. (2008). Some practical guidance for the implementation of propensity score matching. Journal of economic surveys, 22(1), 31-72. 
Carlino, G., \& Kerr, W. R. (2014). Agglomeration and innovation. National Bureau of Economic Research Working Paper 20367.

Carpenter M, Westphal J. 2001. The strategic context of external network ties: examining the impact of board appointments on board involvement in strategic decision making. Academy of Management Journal 44: 639-660.

Casper, S. (2007). How do technology clusters emerge and become sustainable?: Social network formation and inter-firm mobility within the San Diego biotechnology cluster. Research Policy, 36(4):438-455.

Chatterji, A., E. Glaeser, and W. Kerr (2013). Clusters of Entrepreneurship and Innovation, in Lerner, Josh, and Scott Stern (eds.) Innovation Policy and the Economy, Volume 14 (Chicago, IL: University of Chicago Press, 2013).

Coleman, J. S. (1988). Social capital in the creation of human capital. American Journal of Sociology, p. S95-S120.

Combes, P.-P., and Gobillon, L. (2014) The empirics of agglomeration economies. CEPR Discussion Paper No. DP10174.

Dalton D, Daily C, Johnson J, Ellstrand A. (1999) Number of directors and financial performance: A meta-analysis. Academy of Management Journal, 42: 674-684.

Dehejia, R.H. and Wahba, S. (2002). Propensity Score-Matching Methods for Nonexperimental Causal Studies. Review of Economics and Statistics, 84(1):151161.

Duranton, G., \& Puga, D. (2004). Micro-foundations of urban agglomeration economies. Handbook of regional and urban economics, 4, 2063-2117.

Ellison, G., Glaeser, E., and Kerr, W. (2010) What Causes Industry Agglomeration? Evidence from Coagglomeration Patterns, American Economic Review, 100(3): 1195-213.

Feldman, M. and Zoller, T. D. (2012). Dealmakers in place: Social capi- tal connections in regional entrepreneurial economies. Regional Studies, 46(1):23-37.

Feldman, M. P. (2000). Where science comes to life: university bioscience, commercial spinoffs, and regional economic development. Journal of Comparative Policy Analysis: research and practice, 2(3), 345-361.

Fich, E. M., \& Shivdasani, A. (2006). Are busy boards effective monitors? The Journal of finance, 61(2), 689-724.

Glaeser, E. L., Kallal, H. D., Scheinkman, J. A., and Shleifer, A. (1992). Growth in cities. 
Journal of Political Economy, 100(6):1126-1152.

Giuri, P and Mariani M. (2013). When Distance Disappears: Inventors, Education, and the Locus of Knowledge Spillovers, Review of Economics and Statistics, 95 (2): 449-463.

Görg, H., \& Strobl, E. (2007). The effect of R\&D subsidies on private R\&D. Economica, 74(294), 215-234.

Granovetter, M. (1973) The Strength of Weak Ties. American Journal of Sociology 78(6): 1360-1380.

Groen J.A., and Povlika, A.E. (2008) The effects of Hurricane Katrina on Labor Market Outcomes of Evacuees. American Economic Review: Papers and Proceedings, $98: 2,43-48$.

Grogger, J., and Willis, M (2000) The emergence of crack cocaine and the rise in urban crime rates. Review of Economics and Statistics, 82(4): 519-529.

Hargadon, A. and Sutton, R. I. (1997). Technology brokering and innovation in a product development firm. Administrative science quarterly, pages 716-749.

Hausman, N. (2012). University Innovation, Local Economic Growth, and Entrepreneurship. US Census Bureau Center for Economic Studies Paper No. CESWP-12-10.

Heckman, J. J., Ichimura, H., \& Todd, P. (1998). Matching as an econometric evaluation estimator. The Review of Economic Studies, 65(2), 261-294.

Heckman, J. J., Ichimura, H., \& Todd, P. E. (1997). Matching as an econometric evaluation estimator: Evidence from evaluating a job training programme. The review of economic studies, 64(4), 605-654.

Henderson, J. V. (2003). Marshall's scale economies. Journal of urban economics, 53(1), $1-28$.

Jaffe, A. B. (2002). "Building Programme Evaluation into the Design of Public ResearchSupport Programmes," Oxford Review of Economic Policy, 18: 22-34.

Jaffe, A. B., Trajtenberg, M., and Henderson, R. (1993). Geographic localization of knowledge spillovers as evidenced by patent citations. Quarterly Journal of Economics, 108(3):577-598.

Jones, C. I. (2005). Growth and Ideas, in P. Aghion and S.Durlauf (eds.), Handbook of Economic Growth Vol.1, Part2, New York: Elsevier. 
Kenney, M. and Patton, D. (2005). Entrepreneurial geographies: Sup- port networks in three high-technology industries. Economic Geography, 81(2):201-228.

Larcker, D., \& Tayan, B. (2011). Corporate governance matters: A closer look at organizational choices and their consequences. FT Press.

Larcker, D. F., So, E. C., \& Wang, C. C. (2013). Boardroom centrality and firm performance. Journal of Accounting and Economics, 55(2), 225-250.

Lavie, D. (2007). Alliance portfolios and firm performance: A study of value creation and appropriation in the US software industry. Strategic Management Journal, 28(12), 1187-1212.

Lerner, J. (1995). Venture capitalists and the oversight of private firms. The Journal of Finance, 50(1), 301-318.

Lobo, J., \& Strumsky, D. (2008). Metropolitan patenting, inventor agglomeration and social networks: A tale of two effects. Journal of Urban Economics, 63(3): 871884.

Malecki, E. J. (2012). Regional social capital: why it matters. Regional Studies, 46(8):1023-1039.

Marshall, A. (1890). Principles of Economics. Macmillan, London, 8th edition.

Mizruchi, M. (1990) What do interlocks do? An analysis, critique, and assessment of research on interlocking directorates. Annual Review of Sociology, 8(1): 16-32

Mol, M. (2001) Creating wealth through working with others: interorganizational relationships. Academy of Management Executive, 15:150-152

Owen-Smith, J., \& Powell, W. W. (2004). Knowledge networks as channels and conduits: The effects of spillovers in the Boston biotechnology community. Organization Science, 15(1), 5-21.

Ozcan, P., \& Eisenhardt, K. M. (2009). Origin of alliance portfolios: Entrepreneurs, network strategies, and firm performance. Academy of Management Journal, 52(2), 246-279.

Pearl, J. (2000). Causality: models, reasoning and inference. Cambridge: MIT press.

Pennings, J. (1980). Interlocking Directorates: Origins and Consequences of Connections Among Organizations' Board of Directors. San Francisco: JosseyBass 
Powell, W. W., Koput, K. W., and Smith-Doerr, L. (1996). Interorganizational collaboration and the locus of innovation: Networks of learning in biotechnology. Administrative science quarterly, 41(1): 116-145.

Putnam, R. (1995). Bowling alone: America's declining social capital. Journal of democracy, 6:65-65.

Rosenbaum, P. R. and Rubin, D. B. (1983). The central role of the propensity score in observational studies for causal effects. Biometrika, 70(1):41-55.

Rosenthal, S., and Strange, W. (2004), Evidence on the Nature and Sources of Agglomeration Economies, in V. Henderson and J.-F. Thisse (eds), Handbook of Urban and Regional Economics Volume 4, Amsterdam, Elsevier.

Sampson, R. C. (2007). R\&D alliances and firm performance: The impact of technological diversity and alliance organization on innovation. Academy of Management Journal, 50(2), 364-386.

Saxenian, A. (1994). Regional advantage: culture and competition in Silicon Valley and Route 128. Harvard University Press, Cambridge, Mass.

Schoorman, F. D., Bazerman, M. H., \& Atkin, R. S. (1981). Interlocking directorates: A strategy for reducing environmental uncertainty. Academy of Management Review, 6(2), 243-251.

Senor, D. and Singer, S. (2009) Start-up Nation, the Story of Israel's Economic Miracle. Hachette, New York, NY.

Shane, S., \& Cable, D. (2002). Network ties, reputation, and the financing of new ventures. Management Science, 48(3), 364-381.

Stam, W. (2010). Industry event participation and network brokerage among entrepreneurial ventures. Journal of Management Studies, 47(4):625-653.

Storper, M. and Venables, A. J. (2004). Buzz: face-to-face contact and the urban economy. Journal of Economic Geography, 4(4):351-370.

Thompson, P. (2006). Patent citations and the geography of knowledge spillovers: evidence from inventor-and examiner-added citations. Review of Economics and Statistics, 88(2), 383-388.

Uzzi, B. (1997). Social structure and competition in interfirm networks: The paradox of embeddedness. Administrative science quarterly, 35-67. 
Westphal, J. D., Boivie, S., Chng, M., \& Han, D. (2006). The strategic impetus for social network ties: Reconstituting broken CEO friendship ties. Strategic Management Journal, 27(5), 425-445.

Whittington, K. B., Owen-Smith, J., \& Powell, W. W. (2009). Networks, propinquity, and innovation in knowledge-intensive industries. Administrative Science Quarterly, 54(1), 90-122. 


\section{Tables}

Table 1. Distribution of Local Affiliations Among Agents, December 2009

\begin{tabular}{lccccc}
\hline & & \multicolumn{3}{c}{ Number of Local Affiliations (\%) } \\
\cline { 3 - 6 } Region & $\begin{array}{c}\text { Number of } \\
\text { Agents }\end{array}$ & One & Two & Three & Four \\
& & & & & \\
& 3,122 & 93.0 & 5.8 & 0.7 & 0.5 \\
Austin & 15,897 & 89.4 & 7.7 & 1.7 & 1.2 \\
Boston & 4,405 & 94.8 & 4.3 & 0.5 & 0.4 \\
Denver & 3,656 & 93.1 & 5.6 & 1.0 & 0.7 \\
Minneapolis & 5,500 & 95.9 & 3.8 & 0.3 & 0.0 \\
Orange County & 2,583 & 95.9 & 3.4 & 0.5 & 0.2 \\
Phoenix & 2,025 & 95.6 & 3.8 & 0.4 & 0.3 \\
Portland & 2,520 & 93.9 & 5.3 & 0.6 & 0.3 \\
Raleigh/Durham & 2,243 & 93.9 & 5.1 & 0.6 & 0.3 \\
Salt Lake City & 31,221 & 86.1 & 9.4 & 2.5 & 2.0 \\
San Francisco & 6,922 & 91.4 & 6.6 & 1.4 & 0.6 \\
San Diego & 5,485 & 92.2 & 6.1 & 1.0 & 0.7 \\
Seattle & 7,132 & 90.1 & 7.2 & 1.6 & 1.1 \\
\hline Mean & & & & & \\
\hline Ne: Actor & & & & & \\
\end{tabular}

Note: Actors are identified through positions as executives or members of boards of directors in life sciences and information technology firms, as defined by Capital IQ. 
Table 2. Summary Statistics: Analytical Sample in 2009 (N=325)

\begin{tabular}{lcc} 
Variable & Mean & Standard Deviation \\
\hline Receives treatment 2009-2012 & 0.046 & 0.210 \\
Employment & 72.31 & 113.43 \\
Sales (\$ millions) & 13.76 & 29.50 \\
Change in corporate parent 2009-2012 & 0.106 & 0.309 \\
Number of pending/current investments & 2.71 & 3.15 \\
Three-year sales growth peer (Quartiles 1-4) & 2.29 & 1.34 \\
First year of operation & 1993.1 & 10.67 \\
Number of affiliated non-dealmakers & 7.52 & 5.24 \\
Total non-dealmaker local links & 8.56 & 6.45 \\
DNB rating & 2.74 & 0.674 \\
PayDex maximum & 76.52 & 5.45 \\
PayDex minimum & 70.69 & 9.08 \\
Male CEO (1=male) & 0.763 & 0.43 \\
Government Contracts (1=yes) & 0.323 & 0.47 \\
Minority Owned (1=yes) & 0.105 & 0.31 \\
Women-owned (1=yes) & 0.117 & 0.32 \\
Foreign-owned (1=yes) & 0.077 & 0.27 \\
Moved location more than once (1=yes) & 0.268 & 0.44 \\
International trade (0=none) & 0.583 & 1.09 \\
Legal Status (3=Corporation) & 2.912 & 0.318 \\
\hline
\end{tabular}

Note: Data come from D\&B and Capital IQ. All data measured in 2009 unless otherwise specifie 
Table 3. Main Estimates of the Effects of Dealmakers on Firm Performance, 2009-2012

Sales (\$ Million)

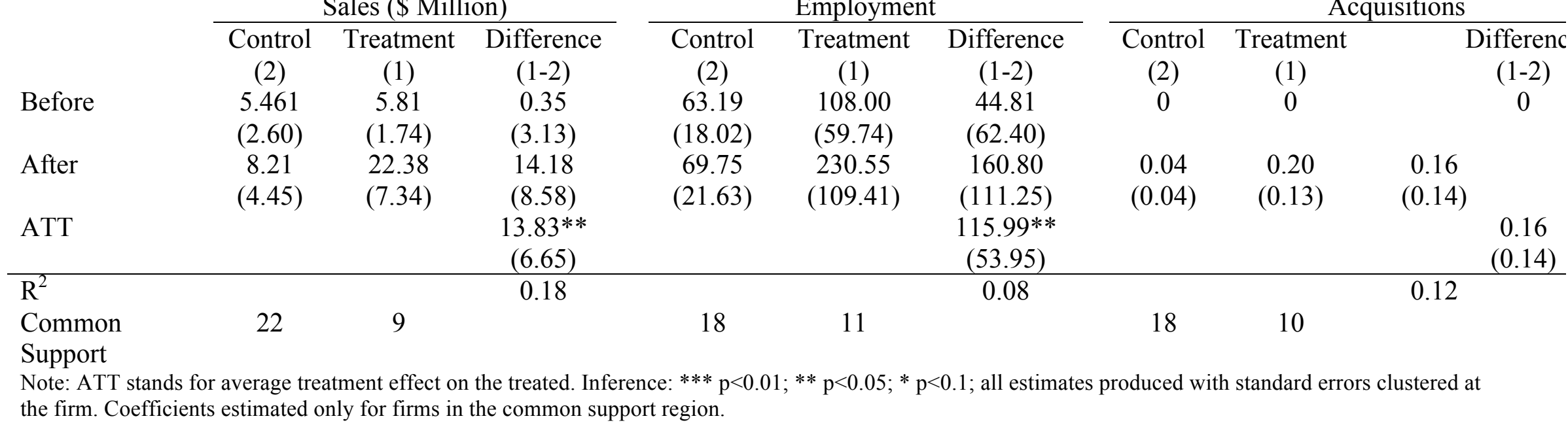


Table 4. Tests of Conditional Independence for Sales, Employment, Sales/Employment and Acquisition Outcomes

\begin{tabular}{|c|c|c|c|c|c|c|c|}
\hline \multirow[b]{2}{*}{ Variable } & \multirow{2}{*}{$\begin{array}{r}\text { Unmatched } \\
\text { Matched }\end{array}$} & \multicolumn{2}{|c|}{ Sales } & \multicolumn{2}{|c|}{ Employment } & \multicolumn{2}{|c|}{ Acquisition } \\
\hline & & $\mathrm{t}$ & $\mathrm{p}>\mathrm{t}$ & $\mathrm{t}$ & $\mathrm{p}>\mathrm{t}$ & $\mathrm{t}$ & $\mathrm{p}>\mathrm{t}$ \\
\hline \multirow[t]{2}{*}{ Employment 2008} & $\mathrm{U}$ & -0.64 & 0.524 & -0.64 & 0.524 & -0.64 & 0.524 \\
\hline & M & 1.16 & 0.255 & 0.45 & 0.656 & 0.99 & 0.326 \\
\hline \multirow[t]{2}{*}{ Employment } & $\mathrm{U}$ & -0.58 & 0.562 & & & -0.58 & 0.562 \\
\hline & M & 1.86 & 0.072 & & & 1.66 & 0.105 \\
\hline \multirow[t]{2}{*}{ Sales 2008} & $\mathrm{U}$ & & & & & & \\
\hline & M & & & & & & \\
\hline \multirow[t]{2}{*}{ Sales (\$mil) } & $\mathrm{U}$ & & & -0.74 & 0.459 & -0.74 & 0.459 \\
\hline & M & & & 0.85 & 0.399 & 1.49 & 0.146 \\
\hline \multirow[t]{2}{*}{ Sales Growth Peer } & $\mathrm{U}$ & -2.07 & 0.039 & -2.07 & 0.039 & -2.07 & 0.039 \\
\hline & M & -1.53 & 0.136 & -1.25 & 0.22 & -1.37 & 0.179 \\
\hline \multirow[t]{2}{*}{ Firm start year } & $\mathrm{U}$ & 2.8 & 0.005 & 2.8 & 0.005 & 2.8 & 0.005 \\
\hline & M & -1.57 & 0.127 & 0.46 & 0.646 & -1.48 & 0.148 \\
\hline \multirow[t]{2}{*}{ Male CEO } & $\mathrm{U}$ & -2.58 & 0.01 & -2.58 & 0.01 & -2.58 & 0.01 \\
\hline & M & -2.11 & 0.042 & -0.73 & 0.474 & -1.4 & 0.17 \\
\hline \multirow[t]{2}{*}{ Gov't Contracts } & $\mathrm{U}$ & -2.4 & 0.017 & -2.4 & 0.017 & -2.4 & 0.017 \\
\hline & M & 1.8 & 0.081 & -0.24 & 0.812 & 1.36 & 0.183 \\
\hline \multirow[t]{2}{*}{ Minority owned } & $\mathrm{U}$ & -1.69 & 0.091 & -1.69 & 0.091 & -1.69 & 0.091 \\
\hline & M & -1.2 & 0.237 & 1.06 & 0.296 & -0.16 & 0.874 \\
\hline \multirow[t]{2}{*}{ Moved location } & $\mathrm{U}$ & -0.77 & 0.441 & -0.77 & 0.441 & -0.77 & 0.441 \\
\hline & M & 0.26 & 0.793 & -1.03 & 0.31 & 0.23 & 0.819 \\
\hline \multirow[t]{2}{*}{ DNB Rating } & $\mathrm{U}$ & 2.15 & 0.032 & 2.15 & 0.032 & 2.15 & 0.032 \\
\hline & M & 0.76 & 0.455 & -0.15 & 0.878 & -0.06 & 0.956 \\
\hline \multirow[t]{2}{*}{ PayDex Max } & $\mathrm{U}$ & -1.95 & 0.052 & -1.95 & 0.052 & -1.95 & 0.052 \\
\hline & M & -2.02 & 0.051 & -0.4 & 0.692 & -1.7 & 0.097 \\
\hline
\end{tabular}




\begin{tabular}{|c|c|c|c|c|c|c|c|}
\hline \multirow[t]{2}{*}{ PayDex Min } & $\mathrm{U}$ & -2.28 & 0.023 & -2.28 & 0.023 & -2.28 & 0.023 \\
\hline & $\mathrm{M}$ & 0.48 & 0.634 & -0.4 & 0.695 & 0.41 & 0.682 \\
\hline \multirow[t]{2}{*}{ Foreign-owned } & $\mathrm{U}$ & -1.69 & 0.091 & -1.69 & 0.091 & -1.69 & 0.091 \\
\hline & $\mathrm{M}$ & 1.05 & 0.302 & 0.56 & 0.581 & 0.81 & 0.426 \\
\hline \multirow[t]{2}{*}{ Women-owned } & $\mathrm{U}$ & -2.1 & 0.036 & -2.1 & 0.036 & -2.1 & 0.036 \\
\hline & $\mathrm{M}$ & 0.41 & 0.684 & -0.74 & 0.464 & 0.23 & 0.82 \\
\hline \multirow[t]{2}{*}{ Non-DM } & $\mathrm{U}$ & 2.13 & 0.033 & 2.13 & 0.033 & 2.13 & 0.033 \\
\hline & $\mathrm{M}$ & -0.84 & 0.406 & -0.18 & 0.856 & -0.85 & 0.4 \\
\hline \multirow[t]{2}{*}{ Non-DM Links } & $\mathrm{U}$ & 4.56 & 0.000 & 4.56 & 0.000 & 4.56 & 0.000 \\
\hline & $\mathrm{M}$ & -0.98 & 0.336 & -0.44 & 0.662 & -1.01 & 0.319 \\
\hline \multirow[t]{2}{*}{ No trade } & $\mathrm{U}$ & 2.66 & 0.008 & 2.66 & 0.008 & 2.66 & 0.008 \\
\hline & $\mathrm{M}$ & -1.1 & 0.281 & -0.46 & 0.648 & -0.88 & 0.383 \\
\hline \multirow[t]{2}{*}{ Imports \& Exports } & $\mathrm{U}$ & -1.59 & 0.112 & -1.59 & 0.112 & -1.59 & 0.112 \\
\hline & $\mathrm{M}$ & . & • & . & . & . & . \\
\hline \multirow[t]{2}{*}{ Exports only } & $\mathrm{U}$ & -2.14 & 0.033 & -2.14 & 0.033 & -2.14 & 0.033 \\
\hline & $\mathrm{M}$ & 0.85 & 0.402 & -0.22 & 0.83 & 0.81 & 0.422 \\
\hline \multirow[t]{2}{*}{ Imports Only } & $\mathrm{U}$ & -0.8 & 0.421 & -0.8 & 0.421 & -0.8 & 0.421 \\
\hline & $\mathrm{M}$ & 0.63 & 0.535 & 0.75 & 0.46 & 0.4 & 0.691 \\
\hline \multirow[t]{2}{*}{ Proprietorship } & $\mathrm{U}$ & 2.06 & 0.04 & 2.06 & 0.04 & 2.06 & 0.04 \\
\hline & $\mathrm{M}$ & & . & 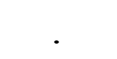 & . & . & 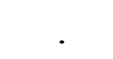 \\
\hline \multirow[t]{2}{*}{ Partnership } & $\mathrm{U}$ & -1.41 & 0.16 & -1.41 & 0.16 & -1.41 & 0.16 \\
\hline & $\mathrm{M}$ & 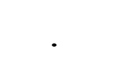 & . & . & . & . & . \\
\hline \multirow[t]{2}{*}{ Corporation } & $\mathrm{U}$ & 0.72 & 0.472 & 0.72 & 0.472 & 0.72 & 0.472 \\
\hline & $\mathrm{M}$ & . & . & . & 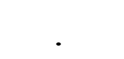 & $r$ & . \\
\hline \multirow[t]{2}{*}{ Non-profit } & $\mathrm{U}$ & -0.38 & 0.703 & -0.38 & 0.703 & -0.38 & 0.703 \\
\hline & $\mathrm{M}$ & & 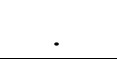 & 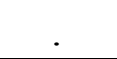 & & 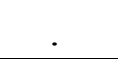 & \\
\hline
\end{tabular}

Note: Unless otherwise specified, all measures are for values of variables measured at 2009. Each matching procedure also included dummy variables for each of the 12 regional economies and 25 industry classes. 
Table 5. Placebo Test Estimates of the Effects of Dealmakers on Firm Sales and Employment, 2006-2009

\begin{tabular}{|c|c|c|c|c|c|c|}
\hline & \multicolumn{3}{|c|}{ Sales (\$ millions) } & \multicolumn{3}{|c|}{ Employment } \\
\hline & $\begin{array}{l}\text { Control } \\
(2)\end{array}$ & $\begin{array}{l}\text { Treatment } \\
\text { (1) }\end{array}$ & $\begin{array}{l}\text { Difference } \\
(1-2)\end{array}$ & $\begin{array}{l}\text { Control } \\
(2)\end{array}$ & $\begin{array}{l}\text { Treatment } \\
\text { (1) }\end{array}$ & $\begin{array}{l}\text { Difference } \\
(1-2)\end{array}$ \\
\hline Before & $\begin{array}{l}6.474 \\
(1.163)\end{array}$ & $\begin{array}{l}10.638 \\
(5.885)\end{array}$ & $\begin{array}{l}4.164 \\
(5.998)\end{array}$ & $\begin{array}{l}56.42 \\
(10.753)\end{array}$ & $\begin{array}{l}53.58 \\
(14.253)\end{array}$ & $\begin{array}{l}-2.837 \\
(17.854)\end{array}$ \\
\hline After & $\begin{array}{l}7.522 \\
(1.256)\end{array}$ & $\begin{array}{l}15.234 \\
(10.395)\end{array}$ & $\begin{array}{l}7.712 \\
(10.471)\end{array}$ & $\begin{array}{l}61.705 \\
(11.386)\end{array}$ & $\begin{array}{l}99.33 \\
(55.92)\end{array}$ & $\begin{array}{l}37.628 \\
(55.109)\end{array}$ \\
\hline ATT & & & $\begin{array}{l}3.548 \\
(4.650) \\
\end{array}$ & & & $\begin{array}{l}40.466 \\
(42.537) \\
\end{array}$ \\
\hline R2 & & & 0.024 & & & 0.032 \\
\hline Common Support & 68 & 11 & & 62 & 12 & \\
\hline
\end{tabular}




\section{Appendix A: Results from Propensity Score Estimation}

Propensity scores are produced using the probit estimator, where a treatment dummy variable $(0=$ control; $1=$ treatment $)$ is the dependent variable. Results from this procedure are presented below, and are the inputs into the estimation of propensity scores.

Table A1: Estimation of Propensity Scores (Probit)

Sales (\$mil) Employment Acquisition

\begin{tabular}{|c|c|c|c|}
\hline Employment (2008) & -0.018 & -0.005 & -0.020 \\
\hline Employment & 0.009 & & 0.014 \\
\hline Sales (\$mil) & & 0.002 & -0.031 \\
\hline Sales Growth Peer & $-.915^{* *}$ & $-0.945 * *$ & $-0.968 * *$ \\
\hline Firm start year & -0.007 & -0.001 & -0.001 \\
\hline Male CEO & -1.484 & -1.317 & -1.513 \\
\hline Gov't Contracts & -1.171 & -1.106 & -1.479 \\
\hline Minority Owned & -0.501 & -0.359 & -0.710 \\
\hline Moved location & 0.110 & 0.047 & 0.173 \\
\hline DNB Rating & -0.048 & -0.019 & -0.111 \\
\hline PayDex Max & 0.054 & 0.056 & 0.050 \\
\hline PayDex Max & -0.042 & -0.040 & -0.048 \\
\hline Foreign Owned & -0.612 & -1.252 & -0.509 \\
\hline Women Owned & -0.045 & -0.199 & 0.253 \\
\hline Non-DM & $-0.471^{*}$ & $-0.463 *$ & $-0.537 *$ \\
\hline Non-DM links & $0.595 * *$ & $0.595 * *$ & $0.658 * *$ \\
\hline SF Bay Area & 1.003 & 0.753 & 1.558 \\
\hline Seattle & 0.915 & 0.957 & 1.336 \\
\hline San Diego & 1.702 & 1.335 & 2.263 \\
\hline Phoenix & 0.747 & 0.568 & 1.461 \\
\hline Boston & -0.342 & -0.478 & 0.014 \\
\hline Application Software & -3.828 & $-3.771 *$ & $-3.918^{*}$ \\
\hline Communication Equipment & $-3.694 * *$ & $-3.513 *$ & $-3.800 * *$ \\
\hline Computer Hardware & -2.255 & -2.317 & -2.288 \\
\hline Electronic Equipment & -2.721 & -2.758 & -2.284 \\
\hline Health care Technology & $-6.093 * *$ & $-6.338 * *$ & $-6.402 * *$ \\
\hline Health care Equipment & -6.666 & $-6.596 * *$ & $-6.816^{* *}$ \\
\hline Information Tech. Consulting & $-3.841 * *$ & -3.193 & -3.798 \\
\hline Internet Software/Services & -4.747 & $-4.890 * *$ & $-4.625^{* *}$ \\
\hline Pharmaceuticals & $-5.164 * *$ & $-5.020 * *$ & $-5.511 * *$ \\
\hline Importer \& Exporter & 0.782 & 0.375 & 0.844 \\
\hline Importer Only & 2.231 & 1.450 & 2.693 \\
\hline Observations & 140 & 140 & 140 \\
\hline Pseudo $\mathrm{R}^{2}$ & 0.58 & 0.57 & 0.59 \\
\hline
\end{tabular}

Note: *** $\mathrm{p}<0.01 ; * * \mathrm{p}<0.05 ; * \mathrm{p}<0.1$ 
${ }^{1}$ Capital IQ defines industries using the Global Industry Classification Standard, which is a set of codes engineered by Standard \& Poor's and MSCI to facilitate effective international standardization of industry codes for the purpose of investment research and analysis. We used aggregate industry codes 35 'Health Care' and 45 'Information Technology'. The former includes detailed biotechnology industries, pharmaceuticals, and other related activities. The latter includes software, internet, IT consulting and other subsectors. Detailed listings are available at: http://www.msci.com/products/indexes/sector/gics/ ${ }^{2}$ Austin, Portland, San Diego, and Phoenix are defined according for Office of Management and Budget (OMB) Metropolitan Area boundaries; for Orange Country, CA, only the single county is used; the remainder are defined according to Consolidated Statistical Area boundaries.

${ }^{3}$ Other thresholds (or even continuous measures) are certainly possible. However, this study opts to remain consonant with Feldman and Zoller's original definition.

${ }^{4}$ Unless otherwise specified, data for 2009 is used.

${ }^{5}$ The analytical sample resembles the overall sample drawn from Capital IQ and D\&B. In two-sample t-tests across these two samples, there were significant differences in terms of employment and some measures of credit. Sales and pending investments were not dissimilar across the two samples. In most cases, even significant differences were small in absolute terms.

${ }^{6}$ Owing to lack of available data on acquisitions from this earlier period, it is not possible to conduct the placebo test for this outcome. 